\title{
Involving patients with type 2 diabetes, hypertension, and hyperlipidaemia in disease management improved outcomes
}

Rachmani R, Levi Z, Slavachevski I, et al. Teaching patients to monitor their risk factors retards the progression of vascular complications in high-risk patients with type 2 diabetes mellitus-a randomized prospective study. Diabet Med 2002;19:385-92.

\section{QUESTION: In patients with type 2 diabetes mellitus, hypertension, and hyperlipidaemia, does involvement in managing their disease improve outcomes?}

\section{Design}

Randomised (unclear allocation concealment*), unblinded,* controlled trial with 4 years of follow up.

\section{Setting}

A hospital diabetes outpatient clinic in Israel.

\section{Patients}

141 patients who were $45-70$ years age (mean age $57 \mathrm{y}$, $51 \%$ women) with type 2 diabetes, blood pressure $>140$ $\mathrm{mm} \mathrm{Hg}$ systolic or $>90 \mathrm{~mm} \mathrm{Hg}$ diastolic, and hyperlipidaemia. Exclusion criteria included diabetes duration $>10$ years, body mass index (BMI) $>35 \mathrm{~kg} / \mathrm{m}^{2}$, smoking, serum creatinine $>176 \mu \mathrm{mol} / \mathrm{l}$, albumin to creatinine ratio $\geq 200 \mathrm{mg} / \mathrm{g}$, and history of vascular surgery. Follow up was $91 \%$.

\section{Intervention}

Patients were allocated to the participation programme (PP) $(n=71)$ or to standard consultation (SC) $(n=70)$. Patients in the PP group attended a 1 hour teaching session and were given detailed written instructions, and a copy of the structured consultation letter that was sent to their family doctor. They were given responsibility for complying with medications, monitoring treatment effects, requesting treatment changes, and achieving and maintaining target blood pressure, low density lipoprotein cholesterol (LDL C), haemoglobin $\mathrm{A}_{1 \mathrm{c}}\left(\mathrm{HbA}_{1 \mathrm{c}}\right)$, and BMI $\left(<25 \mathrm{~kg} / \mathrm{m}^{2}\right.$ for men and $<24 \mathrm{~kg} / \mathrm{m}^{2}$ for women). These patients had the option to initiate a visit or telephone conversation with a consultant when they needed advice. Patients in the SC group were given annual consultation with structured letters provided to their primary care physician. Patients in both groups received medical care by their primary care physicians.

\section{Main outcome measures}

Main outcomes were change in the glomerular filtration rate (GFR) and change in the urinary albumin to creatinine ratio. Secondary outcomes were changes in systolic and diastolic blood pressure, $\mathrm{LDL} \mathrm{C}$, and $\mathrm{HbA}_{1 \mathrm{c}}$ concentrations.

\section{Main results}

Analysis was by intention to treat. At 4 years, the PP group had a higher mean estimated GFR (98 $v 91$ $\mathrm{ml} / \mathrm{min}$ per $1.73 \mathrm{~m}^{2}, \mathrm{p}<0.05$ ) and a lower mean urinary albumin to creatinine ratio $(44 v 69 \mathrm{mg} / \mathrm{g}, \mathrm{p}<0.05)$ than the SC group. Fewer patients in the PP group developed nephropathy (defined as an albumin to creatinine ratio $>300 \mathrm{mg} / \mathrm{g}$ ), new incidences of retinopathy, and cardiovascular events (table). The PP group showed lower mean systolic blood pressure (142 v $148 \mathrm{~mm} \mathrm{Hg}$, $\mathrm{p}<0.05)$, mean diastolic blood pressure $(84 v 88 \mathrm{~mm}$ $\mathrm{Hg}, \mathrm{p}<0.05)$, mean LDL C (114 v $124 \mathrm{mg} / \mathrm{dl}, \mathrm{p}=0.01)$, and mean $\mathrm{HBA}_{1 \mathrm{c}}$ levels $(8.2 \%$ v $8.9 \%, \mathrm{p}=0.04)$ than the SC group.

\section{Conclusion}

In patients with type 2 diabetes mellitus, hypertension, and hyperlipidaemia, participation in disease management improved outcomes.

*See glossary.
Source of funding: no external funding.

For correspondence: Professor M Ravid,

Kfar-Sava, Israel. motriv@clalit.org.il

Abstract and commentary also published in $A C P$ Journal Club Meir Hospital,

Patient participation $(P P) v$ standard consultation (SC) for type 2 diabetes, hypertension, and hyperlipidaemia at 4 yearst

\begin{tabular}{lrrcc} 
Outcomes & PP & SC & RRR $(95 \%$ Cl) & NNT (CI) \\
Nephropathy & $0 \%$ & $6 \%$ & $100 \%(8$ to 100$)$ & $18(7$ to 251$)$ \\
\hline New retinopathy cases & $8 \%$ & $24 \%$ & $65 \%(20$ to 85$)$ & $6(4$ to 26$)$ \\
\hline Cardiovascular events & $34 \%$ & $51 \%$ & $34 \%(3$ to 56$)$ & $6(3$ to 80$)$ \\
\hline
\end{tabular}

†Abbreviations defined in glossary; RRR, NNT, and $\mathrm{Cl}$ calculated from data in article.

\section{COMMENTARY}

The study by Rachmani $e$ al adds to the literature on the benefits of actively involving patients in self management. Study participants were selected from a diabetes outpatient clinic in an academic hospital. Although participants were referred from primary care, they were a high risk group with other cardiovascular risk factors. It is possible that the PP may not be similarly effective in primary care centres without academic input.

Participants in the PP group were provided with individualised, detailed instructions. These participants showed clinically and statistically significant improvement in risk factor management, which led to lower blood pressure, $\mathrm{HBA}_{10}$ and cholesterol concentration. However, interestingly, target concentrations were still not achieved.

This study was not designed to assess such health outcomes as cardiovascular and microvascular events. Other studies, such as the United Kingdom Prospective Diabetes Study ${ }^{1}$ and the Heart Protection Study, ${ }^{2}$ have shown that changes in risk factor control (eg, blood glucose, blood pressure, and cholesterol concentrations) result in improved health outcomes.

A worldwide trend exists towards self management of chronic disease. The recent introduction of Medicare funding in the US for diabetes education is an acknowledgment that funding organisations recognise the value of educating patients and building their capacity for self management. This study will help those designing future education programmes for managing diabetes and other chronic diseases. Pat Phillips, MBBS, MA, FRACP Queen Elizabeth Hospital

Woodville, South Australia, Australia

1 UK Prospective Diabetes Study (UKPDS) Group. Intensive blood glucose control with sulphonylureas or insulin compared with conventional treatment and risk of complicasulphonylureas or insulin compared with conventional treatment and risk of complica-
tions in patients with type 2 diabetes (UKPDS 33). Lancet 1998;352:837-53.

2 Heart Protection Study Collaborative Group. MRC/BHF Heart Protection Study of cholesterol lowering with simvastatin in 20,536 high-risk individuals: a randomised placebo-controlled trial Lancet 2002:360:7-29. 